Title:

The roots of ruthless: Variation as a window on representation

Author:

Hendrik De Smet

Affiliation:

University of Leuven / Research Foundation - Flanders

Address:

Blijde-Inkomststraat 21, PO 3308

3000 Leuven

Belgium

E-mail:

hendrik.desmet@arts.kuleuven.be 


\title{
The roots of ruthless
}

Variation as a window on representation ${ }^{1}$

[AUTHOR]

[AFFILIATION]

\begin{abstract}
An alternative method is explored for probing the mental representation of language by studying variation across language users. It is proposed that linguistic variation between language users reveals language-internal consistencies that are determined by how linguistic material is mentally represented. By examining such consistencies in corpus data light can be shed on the nature of mental representation itself. This thesis is illustrated by a case-study on the relation between semi-opaque derivations (e.g. ruthless) and fully segmentable forms with the same suffix (e.g. sightless). Using data from the New York Times Annotated Corpus, it is demonstrated that language users whose usage relies more heavily on the segmentable forms are also more likely to use the semi-opaque forms. This pattern in the variation across language users indicates that semi-opaque derivations remain related to the derivational paradigm from which they derive, which relation can be stated in terms of morphological schemas. While the casestudy thus shows that variation between language users can be exploited for the study of representation, it also reveals some of the problems that are to be addressed if the method is to be developed further. The problems are discussed and some solutions and further possibilities are suggested.
\end{abstract}

\footnotetext{
${ }^{1}$ [ACKNOWLEDGEMENT]
} 
Corpora reveal variation that we are all familiar with yet mostly prefer to ignore. This is the variation due to the idiosyncrasies of individual language users. Often, corpora are designed to downplay the effects of idiosyncrasy, by making sure that large numbers of language users are represented in the corpus and by restricting the amount of material contributed by any single language user. I would like to propose here, however, that idiosyncrasies can be interesting in their own right and might be exploited as a heuristic tool in linguistic research. If it is assumed that any form of variation between language users must reflect (minor) differences in mental representation, it follows that any patterns or tendencies found in this variation might reveal something about the organization of mental representations.

In what follows, this general idea is to be explored by means of a small case-study on English semi-opaque derivations. Semi-opaque derivations are understood here to be derivations of the type ruthless or squeamish, which have a recognizable affix (-less, as in helpless, painless, etc.; -ish as in sheepish, boyish, etc.) but whose stem (ruth-, squeam-) occurs neither as an independent form nor as a bound root in any other words. The question to be addressed is whether these semi-opaque forms participate in a paradigm of derivations based on the same affix - that is, whether the representations of forms like ruthless are somehow linked to the representations of fully segmentable forms like helpless or painless. The issue is of theoretical interest, because if semiopaque forms are found to relate to fully segmentable forms, this supports both the idea that segmentability is graded (Baayen \& Hay 2005) and that words are organized into exemplar-based schemas (Bybee \& McClelland 2005), against strictly rule-based conceptions of morphological structure.

How can patterns of variation across language users be exploited to test the relationships between semi-opaque forms and fully segmentable forms? The starting point 
is the observation that language users rely on a given derivational pattern - e.g. -lesssuffixation - to different degrees, resulting in variation in the type and token frequencies for that pattern in their output. At the same time, language users differ in the degree to which they rely on specific words - e.g. ruthless -, resulting in variation in the token frequency for that word in their output. This raises certain expectations. If the word ruthless is in any way linked to the overall group of -less-derivations, it is expected that the variation in the use of the former will correlate with the variation in the use of the latter. That is, if the word ruthless somehow instantiates the general pattern of -lessderivation, we expect that anyone frequently relying on -less-derivations will also be more likely to frequently resort to the word ruthless. The assumptions underlying this expectation are, first, that higher frequencies of -less-derivations in usage reflect higher entrenchment for the relevant patterns of activation (cf. Langacker 1987: 100) and, second, that if the -less of ruthless is the same -less as in other-less-derivations it will partly share in the activation patterns for other -less-derivations.

In what follows, this logic is applied to corpus data for a number of semi-opaque derivations involving different suffixes. Next to the case-study, the goal is also to explore and evaluate the proposed method of analyzing the differences between language users. Section 1 discusses the corpus used. Next, Section 2 explains how data have been extracted for the case-study. Section 3 discusses the results from the case-study and their implications. Section 4 summarizes the findings and evaluates the methodology applied, highlighting some of the problems encountered as well as possible solutions and avenues for further research. 


\section{The corpus}

The corpus used in the following case-study is the New York Times Annotated Corpus (NYTAC). There are certain important advantages to this corpus with respect to the particular type of study undertaken here, although it also has a few obvious disadvantages. This section justifies the choice of corpus.

The corpus used for the current type of investigation must meet at least two requirements. First, the corpus needs to be large, so that it contains sufficient data for a sufficiently large number of language users to allow comparison across users. Second, it has to be maximally homogeneous in terms of register and content. If variation between language users is to be interpreted as reflecting differences in mental representation, we must somehow ascertain that it does not reflect anything else. In general, the type of variation at issue here will show up most clearly when language users are aiming to achieve the same communicative goal in the same communicative setting - in other words, what is needed is language users doing the same thing, but doing it in their own way. To be avoided is variation that results from language users doing fundamentally different things.

The NYTAC definitely meets the first requirement and comes reasonably close to satisfying the second. Covering exhaustively all issues of the New York Times from 1987 to 2007, the NYTAC contains well over a billion words of text, with very substantial amounts of text contributed by individual authors. Within this immense body of text there is still considerable variation in text types (news reportage, sports pages, editorials, reviews, columns, weekend specials, obituaries, etc.), but at least one major text type is sufficiently well-represented to serve as a basis for comparison, namely news reportage. 
A second text type for which a relatively large amount of data is available is sports reportage. When focusing on just these text types, register and genre can be kept constant.

The NYTAC also faces at least two potentially serious problems. First, individual journalists are specialized in specific topics (the Middle East, AIDS, domestic politics, etc.), which means that different journalists write about different topics. The frequency of specific lexical items may therefore be codetermined by the specific topics journalists cover rather than by idiolectal usage preferences. One way of counteracting this problem is by selecting lexical items for investigation that are minimally sensitive to topical variation - clearly, no item will be completely insensitive to topic variation, but one can imagine degrees of sensitivity, though at present there is no way of objectifying these intuitions. More reliably, within the actual experiment, the effect of topic sensitivity can to some extent be ruled out by using controls (see Section 3.2 below).

Second, the data from the NYTAC are relatively highly monitored and have been edited. Probably, the ideal type of data would have been spontaneous maximally unmonitored spoken language. This type of data, however, is simply unavailable in the required amounts. For example, the British National Corpus contains 10 million words of spoken text, but distributed over more than 2,000 speakers and in a variety of communicative settings. The Corpus of Contemporary American English has a spoken section of scripted television interactions containing 60 million words, but has no consistent speaker annotation and can only be searched using the online search engine, which for the present purposes would be virtually unfeasible. Similar problems pertain to other spoken and written corpora, with the NYTAC standing out as one of the best options left. It is impossible to assess the degree to which the monitored character of its texts and the possibility of editorial intervention may have interfered with authors' spontaneous usage preferences. However, it can be assumed that monitoring and editing would 
serve to level out individual differences between authors and are, consequently, somewhat unlikely to produce false correlations in the data. A further consideration is that the items and patterns under investigation here are not the subject of stylistic guidelines and probably escape editorial attention. Still, if these assumptions are perhaps soothing, they cannot be verified, so the monitored and edited character of the NYTAC material remains a weakness in the case-study presented below.

\section{Data extraction}

Data extraction has proceeded in three major steps, as described in the following sections. First, two subcorpora have been extracted from the NYTAC to provide the raw material for making comparisons across language users (Section 2.1). Next, the frequencies of occurrence for twelve semi-opaque forms have been established for each of the language users represented in the subcorpora (Section 2.2). Finally, for each of the language users in the subcorpora, the type and token frequencies for the relevant derivational patterns have been established (Section 2.3).

\subsection{Selection of subcorpora}

From the NYTAC, a subcorpus has been extracted containing news reportage texts written by authors for whom minimally 250,000 words of news reportage text is available. Data for 174 authors has been collected in this way, together good for 124 million words of text. A second subcorpus has been extracted containing sports reportage. This second subcorpus is smaller than the first, representing only 47 authors, and totalling 55 million words. The second subcorpus is to be used to verify the results from the first. In 
what follows, the first subcorpus will be referred to as NYTAC-News; the second as NYTAC-Sports. Given the difference in size, NYTAC-News is used below as the primary data source, whereas NYTAC-Sports is used to verify results from NYTAC-News.

\subsection{The frequency of semi-opaque derivations}

In total, twelve semi-opaque derivations have been selected for investigation, as listed in (1):

(1) a. -LESS: feckless, hapless, listless, reckless, ruthless

b. -ISH: garish, outlandish, squeamish

c. -FUL: bashful, doleful, grateful, wistful

For each of these, the frequency of occurrence has been established in the usage of each individual author in NYTAC-News and NYTAC-Sports. For comparability, frequencies have been recalculated per 100,000 words. The result is a collection of frequency measures for each of the items in (1) for each of the authors in the two subcorpora.

Notice that these frequency measures are not normally distributed. The histogram in Figure 1 illustrates this for grateful. The histogram divides the figures obtained for grateful into 10 frequency ranges, giving for each range the number of authors in NYTAC-News whose usage falls within that range. As can be seen, a few authors use grateful a lot (between 2 and 5 times per 100,000 words), while most authors use it infrequently (between 0 and 0.5 times per 100,000 words). The skewing gets worse as the overall frequency of the word examined declines. This is illustrated by Figure 2, giving a histogram for listless, which is about eight times less frequent in NYTAC-News than 
grateful. As Figure 2 suggests, the majority of authors in NYTAC-News simply have no attested uses of listless. Presumably, a normal distribution would eventually be obtained with even larger samples per author, at least for relatively frequent items. As it is, the skewed data is all there is to work with, which restricts somewhat the possibilities for statistical testing (see Section 3.1 below).

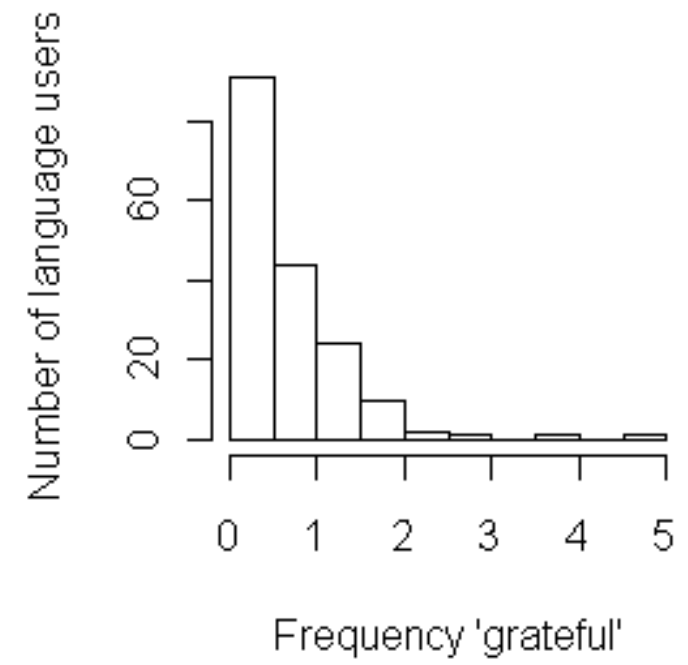

Figure 1. Histogram of the frequency of grateful across language users in NYTAC-news.

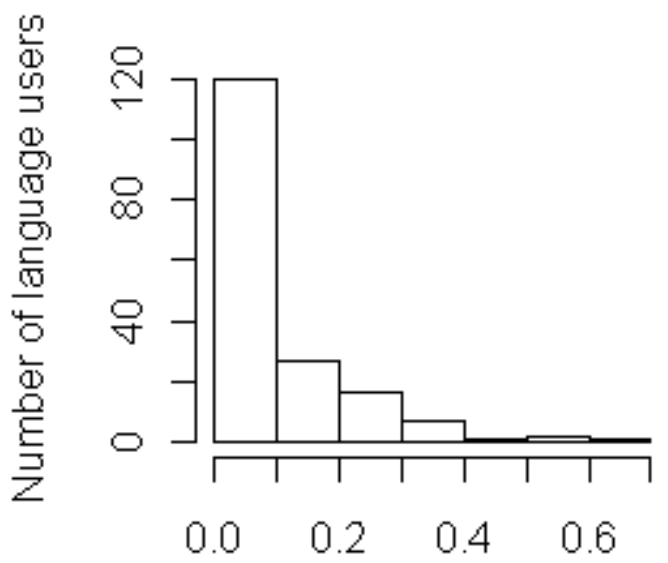

Frequency 'listless'

Figure 2. Histogram of the frequency of listless across language users in NYTAC-news. 


\subsection{The frequency of derivational patterns}

The semi-opaque derivations in (1) involve three different suffixes: -less, -ish and -ful. Of these, -less and -ish are highly productive, even though -ish-derivations are less common than -less-derivations (particularly so in the NYTAC); -ful, by contrast, is only weakly productive in Present-Day English, although (or because) many specific derivations in $-f u l$ are themselves highly frequent. All three suffixes derive adjectives, mostly from nouns but occasionally also from verbs (e.g. mournful) and from other adjectives or from numerals (longish, thirtyish).

For each of the suffixes, authors' individual usage preferences have had to be established. To this purpose, initial searches have been run on all news reportage texts in NYTAC for all words ending in -less, $-i s h$ and $-f u l .^{2}$ The lists of types obtained have then been manually cleared of false hits (e.g. unless, goldfish, mouthful) for all types occurring five times or more. -Less, -ish and -ful-derivations that serve as input to new derivations (e.g. hopelessly, sluggishness, unsuccessful) have been excluded. The items under investigation, listed in (1) above, have also been excluded. The result is three lists of the most common segmentable derivations, one for each derivational affix. These lists are given in (2), in decreasing order of frequency.

(2) a. -LESS: homeless, regardless, endless, relentless, countless, jobless, hopeless, useless, harmless, powerless, helpless, fruitless, wireless, restless, meaningless, needless, tireless, worthless, childless, windowless, topless, stainless,

\footnotetext{
${ }^{2}$ The results of these searches are therefore representative of all news reportage texts in the NYTAC, not just the texts in NYTAC-News as defined above.
} 
breathless, careless, lawless, painless, pointless, doubtless, flawless, seamless, merciless, motionless, ceaseless, landless, toothless, baseless, penniless, spotless, effortless, timeless, bloodless, sleepless, groundless, senseless, limitless, fearless, faceless, priceless, aimless, lifeless, colorless, boundless, roadless, defenseless, stateless, expressionless, smokeless, cloudless, selfless, nameless, shirtless, treeless, shameless, mindless, thankless, headless, bottomless, speechless, odorless, heedless, heartless, rudderless, leaderless, sleeveless, blameless, wordless, clueless, loveless, tasteless, warrantless, pilotless, roofless, fatherless, cordless, cheerless, strapless, bowless, weightless, pitiless, rootless, featureless, humorless, shoeless, remorseless, airless, recoilless, bayless, soulless, peerless, godless, luckless, friendless, joyless, hairless, payless, ageless, moonless, borderless, soundless, emotionless, tieless, shapeless, trackless, thoughtless, coatless, heatless, guileless, windless, paperless, voiceless, snowless, symptomless, waterless, flightless, meatless, mapless, passionless, leafless, collarless, lightless, classless, rimless, directionless, hatless, valueless, numberless, legless, formless, carless, seedless, partyless, rainless, motherless, cashless, driverless, artless, shadeless, entryless, mirthless, changeless, boneless, noiseless, graceless, riderless, meritless, sunless, purposeless, guiltless, parentless, wingless, tactless, helmetless, chairless, gutless, spineless, sexless, spiritless, brainless, limbless, napless, characterless, eyeless, charmless, dauntless, faultless, grassless, armless, witless, jacketless, victimless, fingerless, filterless, backless, sockless, netless, shiftless, glassless, skinless, matchless, beardless, sightless, centerless 
b. -ISH: sluggish, feverish, foolish, hawkish, stylish, sheepish, nightmarish, boyish, dovish, impish, selfish, reddish, bullish, ticklish, bookish, freakish, devilish, brackish, childish, ghoulish, hellish, amateurish, brutish, brownish, clannish, fybish, girlish, rakish, slavish, puckish, raffish, yellowish, pinkish, bearish, boorish, standoffish, grayish, owlish, thuggish, whitish, fiendish, smallish, peevish, bluish, greenish, standish, churlish, purplish, roguish, cartoonish, snappish, longish, modish, baldish, prudish, beamish, snobbish, youngish, clownish, boosterish, pixieish, monkish, loutish, mannish, gelish, 40ish, 50ish, drawish, wonkish, singlish, bendish, schoolmarmish, voguish, faddish, mawkish, coquettish, coltish, squarish, tomboyish, leftish, 30ish, caddish, foppish, piggish, noirish, roundish, no-namish, elfish, waspish

c. $\quad$-FUL: powerful, successful, careful, peaceful, painful, useful, forceful, hopeful, fearful, faithful, helpful, beautiful, colorful, harmful, cheerful, youthful, meaningful, mindful, graceful, skillful, doubtful, respectful, thoughtful, awful, gleeful, playful, wonderful, dutiful, rueful, tearful, lawful, plentiful, resentful, artful, wasteful, fateful, watchful, wrongful, rightful, woeful, scornful, willful, stressful, mournful, fitful, wishful, distasteful, fanciful, vengeful, joyful, purposeful, fruitful, truthful, merciful, distrustful, sorrowful, thankful, disdainful, dreadful, pitiful, bountiful, resourceful, sinful, healthful, masterful, shameful, disrespectful, soulful, eventful, tasteful, delightful, mistrustful, insightful, boastful, remorseful, worshipful, forgetful, hurtful, tactful, hateful, fretful, deceitful

The lists in (2) have served as the basis for examining the variation between individual language users in their reliance on each of the three derivational patterns. Notice at this 
point that the majority of adjectives derived with -less, -ish and -ful denote properties that are emotionally-laden, conveying a positive or (more commonly) negative evaluation, and must mostly be used to characterize a human referent. This is true also of the semi-opaque derivations in (1) above. High frequencies for -less, -ish or -ful-derivations in a specific language user might therefore reflect a usage preference for evaluative adjectives rather than for the derivational pattern per se - a problem to be discussed in Section 3.2 below.

An author's reliance on a derivational pattern can be measured using type or token frequency. Both measures have been calculated. A 250,000-word sample of continuous text has been extracted for each author, on the basis of which the type frequency for each author for each derivational pattern has been established, using the types listed in (2) above. ${ }^{3}$ Still using the types in (2), token frequencies have been established for the whole body of text produced by any individual author (recalculated to frequencies per 100,000 words).

The two measures turn out to be fairly highly correlated and would therefore seem to be about equally good indices of an author's reliance on a derivational pattern. However, the token frequency measure occasionally produces extreme outliers, which are invariably due to exceptionally high token frequencies for single lexical items in the usage of individual authors. Further, the value for the token frequency measure is primarily determined by the high-frequency words, but these may in fact be stored autonomously and might therefore not participate in the derivational paradigm that originally gave rise to them (Bybee 2006). For these reasons, the type frequency count

\footnotetext{
${ }^{3}$ Sample size per author has to be held constant, because type frequencies increase nonlinearly with sample size. Simply put, as the sample grows bigger, possible new types get used up, and type frequency grows less and less fast (cf. Baayen 2008).
} 
has been chosen as the more reliable measure. Notice, finally, that the type frequency measure is approximately normally distributed (though still with a noticeable skew), as illustrated for -less in Figure 3.

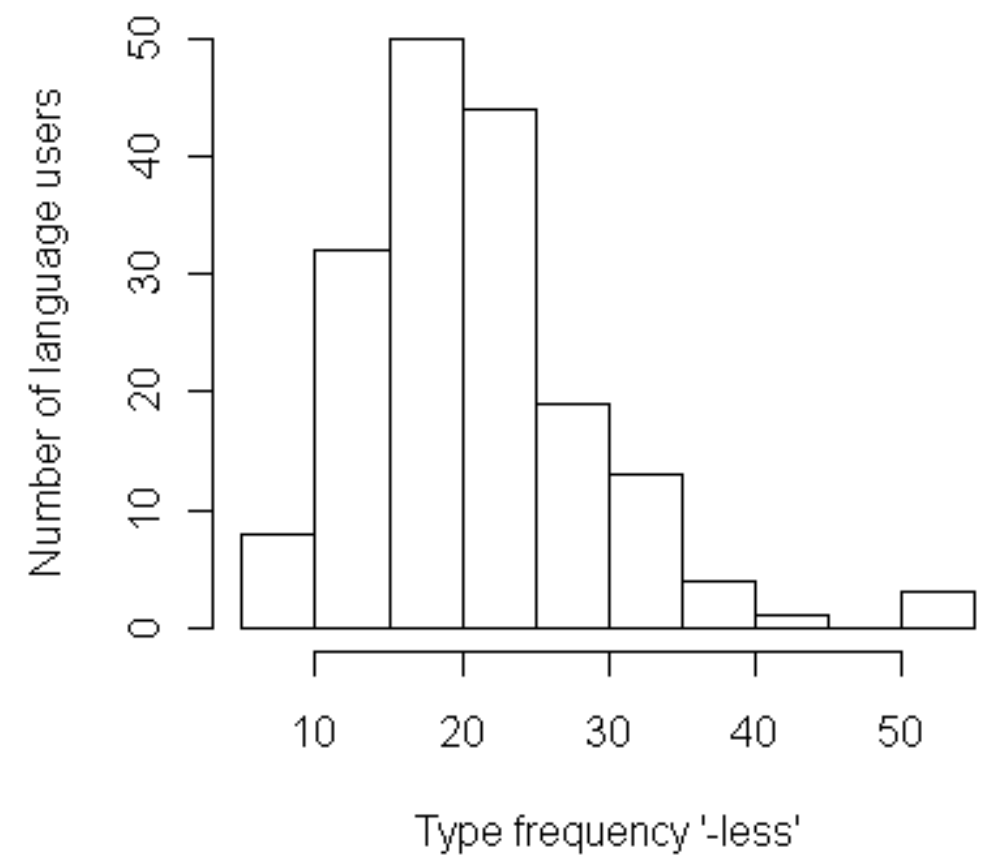

Figure 3. Histogram of the type frequency of -less-derivations across language users in NYTAC-News.

\section{Results and discussion}

Having obtained figures for the token frequencies of specific semi-opaque forms and the type frequencies for derivational patterns, we are in a position to ask whether one variable can predict anything about the other. Pursuing this question, it is found that correlations exist. In general, language users who produce many -less-derivations are also more likely to produce semi-opaque forms like ruthless, reckless, hapless, feckless 
and listless. Language users who produce many -ish-derivations are also more likely to produce semi-opaque forms like squeamish, outlandish and garish. Language users who produce many -ful-derivations are also more likely to produce semi-opaque forms like grateful, doleful, bashful and wistful. In what follows, Section 3.1 presents the figures in some detail, discussing along the way how these figures can be ordered and interpreted; Section 3.2 tests against some possible confounds; and Section 3.3 discusses the results.

\subsection{The figures}

There are a number of ways to test for relations between the variables for which measures have been collected. At its strongest, the correlation between a single semi-opaque form's token frequency and the type frequency of the corresponding derivational pattern can be detected in a scatterplot of the two variables. This is shown for the use of grateful in NYTAC-News in Figure 4. Each dot in Figure 4 represents one author in NYTAC-News, specifying the token frequency of grateful and the type frequency for -fulderivations in their usage. Dots are semi-transparent, so that overlapping data-points appear as darker-coloured dots. To diminish the skewedness of the distribution of token frequency measures for grateful (see Section 2.2 above), the token frequencies have been logarithmically transformed. As can be seen from Figure 4, there is a clear correlation between the two variables: the higher the type frequency of -ful-derivations in a given author's usage, the more frequently s/he uses grateful. 


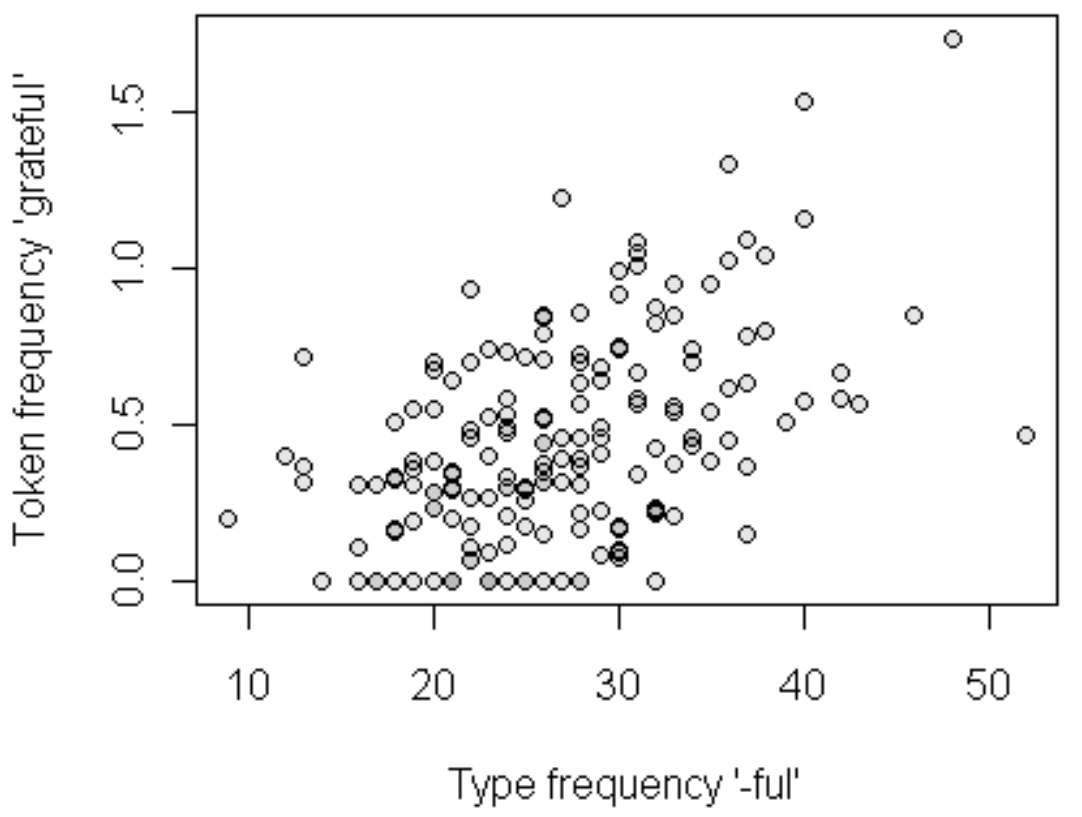

Figure 4. Scatterplot of the token frequency of grateful (per 100,000 words, logarithmically transformed) and the type frequency of -ful-derivations for individual authors in NYTAC-News.

An $\mathrm{R}^{2}$ value can be calculated that gives an idea of the degree of correlation between the two variables. For the grateful-data in Figure 4 , the $\mathrm{R}^{2}$ value is 0.24 , meaning that the independent variable (here, the type frequency of $-f u l$ ) can explain about $24 \%$ of the variation in the dependent variable (the token frequency of grateful). This is a fairly strong correlation. However, the calculation of $\mathrm{R}^{2}$ assumes normal distributions in the data, which assumption is not entirely met here, even after logarithmic transformation of the token frequency measures.

This problem becomes much more severe for lower-frequency items. Figure 5 illustrates this with the scatterplot for listless in NYTAC-News. Again, overlapping data-points appear as darker-coloured dots. As the plot shows, most authors in NYTAC- 
News simply have no recorded instance of listless, resulting in a heavily skewed distribution, despite logarithmic transformation of the token frequency measure. As a result, calculation of $\mathrm{R}^{2}$ is of little use in this case.

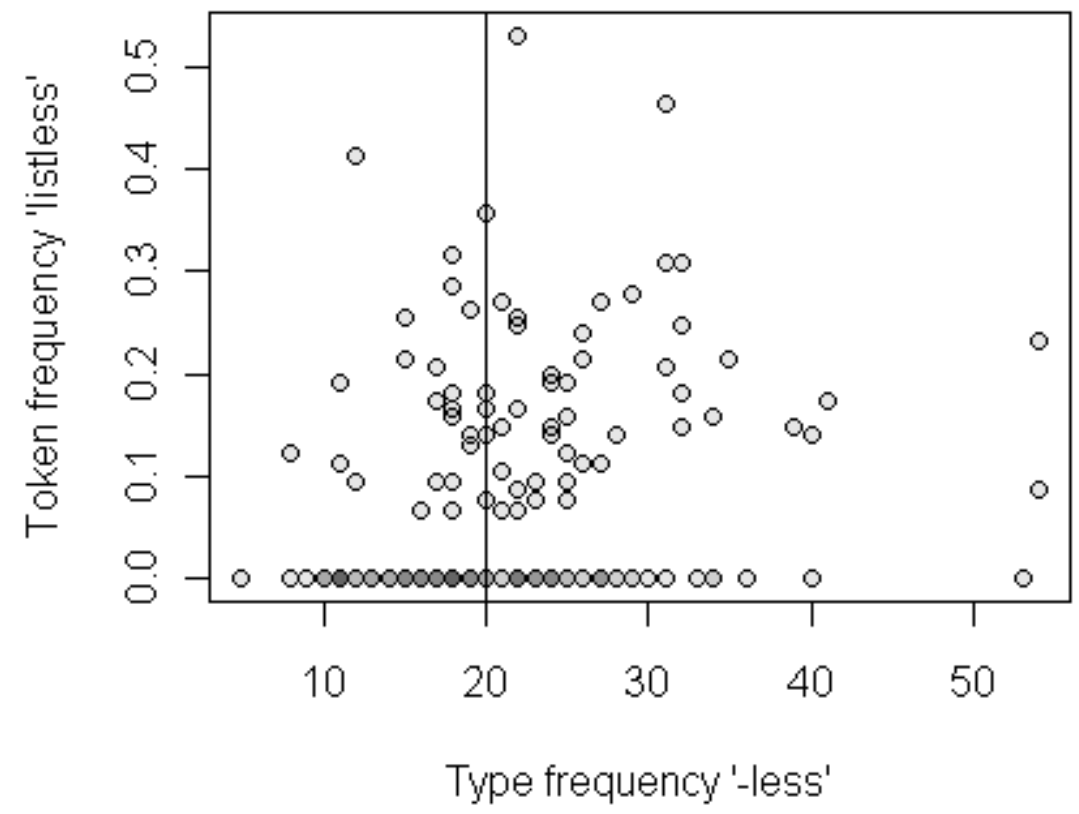

Figure 5. Scatterplot of the token frequency of listless (per 100,000 words, logarithmically transformed) and the type frequency of -less-derivations for individual authors in NYTAC-News.

Even so, visual inspection of the scatterplot in Figure 5 suggests a (slight) trend in the data. The vertical line in Figure 5 marks the median value for the type frequency measure, thereby dividing the set of authors in NYTAC-News into two groups - to the left those whose use of -less-derivations falls below the median, to the right those whose usage exceeds the median. It can be seen that to the right of the line, among the authors relying more heavily on -less-derivation, fewer authors have produced no instances of listless and the average token frequency of listless across authors appears a little higher. 
These impressions can be verified. The average frequency for listless across all authors in NYTAC-News is 0.81 per million words, but for the group of high -less-users, the average frequency is 1.03 , whereas it is 0.60 for the group of low -less-users. This difference is not simply due to a few extreme values. Among the group of high -lessusers, 37 out of 84 authors have a higher-than-average frequency for listless, whereas among the group of low -less-users, an above-average frequency is found in only 19 out of 81 authors - a difference that is statistically significant $\left(\chi^{2} 7.80, p=0.005\right)$. Further, among the low -less-users, listless is absent altogether in the usage of 60 authors out of 81, while among the high -less-users, it is absent in only 44 authors out of 84 - a difference that is again statistically significant $\left(\chi^{2} 8.33, \mathrm{p}=0.004\right) .{ }^{4} \mathrm{In}$ sum, even though the trend for listless is not as outspoken as for grateful, a clear trend can still be demonstrated: high -less-users tend to be also high listless-users, just as high -ful-users tend to be high grateful-users.

The methodology applied to listless can be extended to the other semi-opaque derivations. The above suggests a number of ways of measuring the differences between high and low users of a given suffix. However, comparing average token frequencies across groups of users does not produce results that can be tested for statistical significance and is therefore less useful as a method. Further, distinguishing users of a given form from non-users does not work for high-frequency items that everyone uses. Therefore, I have chosen to divide authors between high and low users of a given semiopaque form by comparing their token frequency to the mean token frequency, even though, as will be shown, this method is not without its problems either.

\footnotetext{
${ }^{4}$ Note that for these statistics I have not counted the authors whose type frequency score coincides with the median.
} 
Table 1 does this for the semi-opaque forms on -less in the usage of the authors in NYTAC-News. Specifically, the authors have been divided into high and low -lessusers on the basis of their type frequency for fully segmentable -less-derivations, using the median type frequency over all authors as dividing criterion. For any given semiopaque form, these two groups of authors are then subdivided into high and low users of that specific form, on the basis of the token frequency of that form in their usage, using the mean token frequency over all authors as dividing criterion. The same is done for the semi-opaque forms on -ish and -ful in Tables 2 and 3 respectively. In each table, the rightmost column gives the result of a chi-squared test showing the degree of statistical significance for the differences between values in a row. For rows with one or more value below 5, a Fisher's exact test has been used. 


\begin{tabular}{|c|c|c|c|c|c|}
\hline \multirow{2}{*}{ A } & \multicolumn{2}{|c|}{ Low-less-users } & \multicolumn{2}{|c|}{ High -less-users } & \multirow{2}{*}{ Significance } \\
\hline & Low A-users & High A-users & Low A-users & High A-users & \\
\hline Feckless & $72(89 \%)$ & $9(11 \%)$ & $72(86 \%)$ & $12(14 \%)$ & $\begin{array}{r}\chi^{2} 0.37, p= \\
0.541\end{array}$ \\
\hline Hapless & $61(75 \%)$ & $20(25 \%)$ & $48(57 \%)$ & $36(43 \%)$ & $\begin{array}{r}\chi^{2} 6.07, p= \\
0.014\end{array}$ \\
\hline Listless & $62(77 \%)$ & $19(23 \%)$ & $47(56 \%)$ & $37(44 \%)$ & $\begin{array}{r}\chi^{2} 7.80, p= \\
0.005\end{array}$ \\
\hline Reckless & $49(73 \%)$ & $22(27 \%)$ & $52(62 \%)$ & $32(38 \%)$ & $\begin{array}{r}\chi^{2} 2.24, p= \\
0.135\end{array}$ \\
\hline Ruthless & $66(81 \%)$ & $15(19 \%)$ & $40(46 \%)$ & $44(54 \%)$ & $\begin{array}{r}\chi^{2} 20.58, p= \\
0.000\end{array}$ \\
\hline
\end{tabular}

Table 1. -Less-usage and use of semi-opaque -less-forms in individual authors in NY-

TAC-News. 


\begin{tabular}{|c|c|c|c|c|c|}
\hline \multirow{3}{*}{ A } & \multicolumn{2}{|c|}{ Low -ish-users } & \multicolumn{2}{|c|}{ High -ish-users } & \multirow{3}{*}{ Significance } \\
\hline & Low A- & High A- & Low A- & High A- & \\
\hline & users & users & users & users & \\
\hline \multirow[t]{2}{*}{ Garish } & \multirow[t]{2}{*}{$60(71 \%)$} & \multirow[t]{2}{*}{$24(29 \%)$} & \multirow[t]{2}{*}{$42(56 \%)$} & \multirow[t]{2}{*}{$33(44 \%)$} & $\chi^{2} 4.10, p=$ \\
\hline & & & & & 0.043 \\
\hline \multirow{2}{*}{ Outlandish } & \multirow{2}{*}{$61(73 \%)$} & \multirow{2}{*}{$23(27 \%)$} & \multirow{2}{*}{$43(57 \%)$} & \multirow{2}{*}{$23(43 \%)$} & \\
\hline & & & & & 0.043 \\
\hline \multirow{2}{*}{ Squeamish } & \multirow{2}{*}{$68(84 \%)$} & \multirow{2}{*}{$16(16 \%)$} & \multirow{2}{*}{$50(67 \%)$} & \multirow[t]{2}{*}{$25(33 \%)$} & $\chi^{2} 4.23, p=$ \\
\hline & & & & & 0.04 \\
\hline
\end{tabular}

Table 2. -Ish-usage and use of semi-opaque -ish-forms in individual authors in NYTACNews.

\begin{tabular}{|c|c|c|c|c|c|}
\hline \multirow{2}{*}{ A } & \multicolumn{2}{|c|}{ Low -ful-users } & \multicolumn{2}{|c|}{ High -ful-users } & \multirow{2}{*}{ Significance } \\
\hline & Low A-users & High A-users & Low A-users & High A-users & \\
\hline Bashful & $72(94 \%)$ & $5(6 \%)$ & $57(69 \%)$ & $26(31 \%)$ & $\begin{array}{r}\chi^{2} 15.77, p= \\
0.000\end{array}$ \\
\hline Doleful & $76(99 \%)$ & $1(1 \%)$ & $68(82 \%)$ & $15(18 \%)$ & $\mathrm{p}=0.000$ \\
\hline Grateful & $62(81 \%)$ & $15(19 \%)$ & $38(46 \%)$ & $45(54 \%)$ & $\begin{array}{r}\chi^{2} 20.56, p= \\
0.000\end{array}$ \\
\hline Wistful & $65(84 \%)$ & $12(16 \%)$ & $35(42 \%)$ & $48(58 \%)$ & $\begin{array}{r}\chi^{2} 30.42, p= \\
0.000\end{array}$ \\
\hline
\end{tabular}


For nearly all adjectives, the figures in Tables 1 through 3 reveal significant trends, and they consistently point in the same direction. An author's usage of semi-opaque forms correlates with their use of the corresponding affix. Results are not statistically significant $(\mathrm{p}>0.05)$ for reckless and feckless, but note that for both adjectives the mean token frequency per million words differs between the two groups of authors. Reckless occurs on average 8.02 times per million words among high -less-users but only 5.01 times per million words among low -less-users. Feckless averages at 0.54 instances per million words among high -less-users, but at 0.37 instances per million words for low -less-users. In other words, the use of these adjectives still seems to confirm the general trend.

Importantly, the differences between p-values in the Tables above are difficult to interpret. This is so for a number of reasons, which also lay bare some general weaknesses in the present approach. First, notice that for any semi-opaque adjective A, the share of low A-users and high A-users is usually unequal - typically with a greater overall share of low A-users - and that this inequality varies from one adjective to another. This is unfortunate, as differences in the distribution of high and low A-users can be spotted most easily if there is a roughly equal share of high and low A-users to distribute in the first place. Feckless, for instance, has only 21 high feckless-users against 144 low feckless-users. In comparison, for ruthless there are 59 high ruthless-users against 106 low ruthless-users. Consequently, a difference in the distribution of feckless-users over high and low -less-users will be much harder to pick up than a difference in the distribution of ruthless-users. If the difference is too small, it may stay below the significance threshold for feckless but not for ruthless.

Second, the measurements that distinguish high from low users vary in reliability. For low-frequency items like feckless it is more difficult to reliably establish frequency 
differences in different authors' usage than for high-frequency items. The division between high and low A-users is therefore built on more solid foundations for highfrequency adjectives than for low-frequency adjectives, where the difference between high and low A-users may, in the extreme case, boil down to the presence or absence of a single attestation in a given author's output. A similar problem arises when comparing not just across adjectives but also across suffixes. For any suffix $\mathrm{S}$, the division between high S-users and low S-users has been determined on the basis of a type frequency count for S-derivations in a 250,000-word sample for each user. Presumably, this type frequency measure becomes more reliable as the suffix is more frequent. This may explain why the most frequent suffix, -ful, also gives the clearest results, with extremely low p-values, while the least frequent suffix, -ish, yields results that are only weakly significant, with relatively high p-values. For $-i s h$, it is simply more difficult than for -ful to distinguish high S-users from low S-users, because no-one uses -ish all that often.

That said, the weaknesses in the applied methodology do not undermine the general conclusion. For each adjective separately the method produces an interpretable result, which turns out to point in the same direction in all cases. In NYTAC-News, the frequency of semi-opaque derivations in an author's usage is sensitive to that author's use of the corresponding derivational affix.

\subsection{Testing validity}

The validity of the findings presented above has been tested in two ways. First, the procedure used above on NYTAC-News has been applied to NYTAC-Sports, to see if the results from NYTAC-News are confirmed. Second, the procedure has also been applied 
to four adjectives without the suffixes -less, -ish or -ful, in order to rule out some possible alternative explanations for the tendencies observed in the semi-opaque derivations.

Tables 4 through 6 replicate the results from Tables 1 through 3 but using the data from NYTAC-Sports. As NYTAC-Sports is smaller than NYTAC-News, it is not surprising that the findings are somewhat less outspoken, yet the overall tendency is again clear and generally confirms the findings from the previous section. Again, semi-opaque derivations are used more by authors who rely more heavily on the related derivational pattern. For six out of twelve semi-opaque adjectives, the difference is statistically significant or approximates statistical significance $(\mathrm{p}<0.1)$. For the others, the differences between users fall short of being significant but the data still behave roughly as expected, with a consistently higher percentage of high A-users in the right half of the table. This indicates that the findings for semi-opaque forms extend to other data sets.

\begin{tabular}{|c|c|c|c|c|c|}
\hline \multirow{2}{*}{ A } & \multicolumn{2}{|c|}{ Low-less-users } & \multicolumn{2}{|c|}{ High -less-users } & \multirow{2}{*}{ Significance } \\
\hline & Low A-users & High A-users & Low A-users & High A-users & \\
\hline Feckless & $22(100 \%)$ & $0(0 \%)$ & $18(81 \%)$ & $4(19 \%)$ & $\mathrm{p}=0.108$ \\
\hline Hapless & $12(55 \%)$ & $10(45 \%)$ & $14(64 \%)$ & $8(36 \%)$ & $\begin{array}{r}\chi^{2} 0.71, p= \\
0.4\end{array}$ \\
\hline Listless & $18(81 \%)$ & $419(\%)$ & $12(54 \%)$ & $10(45 \%)$ & $p=0.104$ \\
\hline Reckless & $16(73 \%)$ & $6(27 \%)$ & $10(45 \%)$ & $12(54 \%)$ & $\begin{array}{r}\chi^{2} 3.38, p= \\
0.066\end{array}$ \\
\hline Ruthless & $17(77 \%)$ & $5(23 \%)$ & $14(\% 64)$ & $8(36 \%)$ & $\begin{array}{r}\chi^{2} 0.67, p= \\
0.425\end{array}$ \\
\hline
\end{tabular}




\begin{tabular}{lccccr}
\hline & \multicolumn{2}{c}{ Low -ish-users } & \multicolumn{2}{c}{ High -ish-users } & \\
\cline { 2 - 5 } A & Low A- & High A- & Low A- & High A- & Significance \\
& users & users & users & users & \\
\hline Garish & $18(86 \%)$ & $3(14 \%)$ & $9(53 \%)$ & $8(47 \%)$ & $\mathrm{p}=0.037$ \\
Outlandish & $14(67 \%)$ & $7(33 \%)$ & $7(41 \%)$ & $10(59 \%)$ & $\chi^{2} 2.47, \mathrm{p}=$ \\
& & & & & 0.116 \\
Squeamish & $19(90 \%)$ & $2(10 \%)$ & $8(47 \%)$ & $9(53 \%)$ & $\mathrm{p}=0.005$
\end{tabular}

Table 5. -Ish-usage and use of semi-opaque -ish-forms in individual authors in NYTACSports.

Low -ful-users High -ful-users

A Low A-users High A-users Low A-users High A-users

Significance

\begin{tabular}{lrrrrr}
\hline Bashful & $18(78 \%)$ & $5(22 \%)$ & $17(74 \%)$ & $6(26 \%)$ & $\chi^{2} 0.12, \mathrm{p}=$ \\
Doleful & $23(100 \%)$ & $0(0 \%)$ & $15(65 \%)$ & $8(35 \%)$ & $\mathrm{p}=0.004$ \\
Grateful & $18(78 \%)$ & $5(22 \%)$ & $12(52 \%)$ & $11(48 \%)$ & $\chi^{2} 3.45, \mathrm{p}=$ \\
Wistful & $19(83 \%)$ & $4(17 \%)$ & $11(48 \%)$ & $12(52 \%)$ & $\mathrm{p}=0.029$
\end{tabular}

Table 6. -Ful-usage and use of semi-opaque -ful-forms in individual authors in NYTAC-Sports.

For further validation, a testing procedure has been applied involving four control adjectives. Recall that -less, -ish and -ful-derivations, as well as the semi-opaque forms, tend to be evaluative adjectives denoting a usually negative property, mostly of a human 
referent (see (2) above). This means that high usage of -less, -ish or -ful-derivations in a given author might reflect not so much a usage preference for these derivational patterns per se but a broad semantic preference for evaluative adjectives or might even reflect the kind of journalistic topic typically covered by that author. For this reason, four control adjectives have been chosen that would be expected to also correlate positively with -less, -ish and -ful-usage provided that correlations are due to topic variation rather than usage preferences or to broad semantic usage preferences rather than to patternspecific morphological usage preferences.

The control adjectives selected resemble the typical -less, -ish and -ful-derivations in being morphologically complex negative evaluative adjectives. They instantiate two derivational patterns, one of which is very frequent and highly productive (un-derivation), and one of which is infrequent and low in productivity (-somederivation). For each pattern, a highly frequent adjective has been selected (troublesome, unhappy), next to a less frequent adjective (quarrelsome, unreliable). At the same time, for each pattern, one adjective is used almost exclusively with human referents (quarrelsome, unhappy), while the other can also freely occur with non-human referents (troublesome, unreliable).

These four adjectives have been subjected to exactly the same procedure that produced the results presented in Section 3.1, checking whether high usage of a given derivational pattern correlates with high usage of a given adjective. The outcome is given in Table 7. 


\begin{tabular}{|c|c|c|c|c|c|}
\hline \multirow{3}{*}{ A } & \multicolumn{2}{|c|}{ Low-less-users } & \multicolumn{2}{|c|}{ High -less-users } & \multirow{3}{*}{ Significance } \\
\hline & Low A- & High A- & Low A- & High A- & \\
\hline & users & users & users & users & \\
\hline \multirow[t]{2}{*}{ Quarrelsome } & $69(85 \%)$ & $12(15 \%)$ & $66(79 \%)$ & $18(21 \%)$ & $\chi^{2} 0.90, p=$ \\
\hline & & & & & 0.341 \\
\hline \multirow[t]{2}{*}{ Troublesome } & $52(64 \%)$ & $29(36 \%)$ & $58(69 \%)$ & $26(31 \%)$ & \\
\hline & & & & & 0.509 \\
\hline \multirow{2}{*}{ Unhappy } & $52(64 \%)$ & $29(36 \%)$ & $52(62 \%)$ & $32(38 \%)$ & $\chi^{2} 0.09, p=$ \\
\hline & & & & & 0.76 \\
\hline \multirow[b]{2}{*}{ Unreliable } & & & & & $\chi^{2} 0.97, p=$ \\
\hline & $48(59 \%)$ & $33(41 \%)$ & $56(67 \%)$ & $28(33 \%)$ & 0.324 \\
\hline
\end{tabular}

High -ish-users

\begin{tabular}{|c|c|c|c|c|c|}
\hline Quarrelsome & $69(82 \%)$ & $15(18 \%)$ & $61(81 \%)$ & $14(19 \%)$ & $\begin{array}{r}\chi^{2} 0.02, p= \\
0.895\end{array}$ \\
\hline Troublesome & $54(64 \%)$ & $30(36 \%)$ & $50(67 \%)$ & $25(33 \%)$ & $\begin{array}{r}\chi^{2} 0.10, p= \\
0.753\end{array}$ \\
\hline Unhappy & $55(65 \%)$ & $29(35 \%)$ & $46(62 \%)$ & $29(38 \%)$ & $\begin{array}{r}\chi^{2} 0.29, p= \\
0.588\end{array}$ \\
\hline Unreliable & $45(54 \%)$ & $39(46 \%)$ & $53(71 \%)$ & $22(29 \%)$ & $\begin{array}{r}\chi^{2} 4.90, p= \\
0.027\end{array}$ \\
\hline & \multicolumn{2}{|c|}{ Low -ful-users } & \multicolumn{2}{|c|}{ High -ful-users } & \\
\hline Quarrelsome & $66(86 \%)$ & $11(14 \%)$ & $66(80 \%)$ & $17(20 \%)$ & $\begin{array}{r}\chi^{2} 1.06, p= \\
0.303\end{array}$ \\
\hline Troublesome & $56(73 \%)$ & $21(27 \%)$ & $49(59 \%)$ & $34(41 \%)$ & $\begin{array}{r}\chi^{2} 3.32, p= \\
0.068\end{array}$ \\
\hline
\end{tabular}




$$
\begin{array}{lrrrrr}
\text { Unhappy } & 55(71 \%) & 22(29 \%) & 45(54 \%) & 38(46 \%) & \chi^{2} 5.05, \mathrm{p}= \\
& & & & 0.025 \\
\text { Unreliable } & 52(68 \%) & 28(32 \%) & 53(69 \%) & 30(31 \%) & \chi^{2} 0.02, \mathrm{p}=
\end{array}
$$

Table 7. -Less, -ish and ful-usage and use of four control adjectives in individual authors in NYTAC-News.

On the whole, the results in Table 7 suggest that the findings presented in Section 3.1 have not been heavily distorted by topical variation or by broad semantic rather than pattern-specific morphological usage preferences. High -less-usage does not correlate in any obvious way with an increased use of any of the four control adjectives. The same goes for-ish-usage, except that for unreliable the data surprisingly produce a significant but negative correlation with -ish-usage. For -ful-usage the figures in Table 7 might suggest a trend, with a significant positive correlation for unhappy and an almost significant correlation for troublesome, although the evidence is certainly much weaker than for the semi-opaque forms (cf. Tables 3 and 6 above). On the whole, it cannot be ruled out that correlations between the use of a semi-opaque form and the related derivational pattern are reinforced by differences in topic coverage and broad semantic usage preferences (in fact, some such effect is even to be expected), but judging from Table 7 the effect does not appear strong enough to produce on its own the highly significant and consistent correlations actually found. 


\subsection{Interpretation}

No one will doubt that a semi-opaque derivation like ruthless has to be somehow memorized and stored lexically. As ruth-never occurs independently of ruthless, ruthless simply cannot be generated by rule, so there is no other way to produce ruthless than from memory. In this, it differs from fully segmentable forms like painless or sightless, which can in principle also be composed. Nevertheless, the results presented in Section 3.1 show that the use of forms like ruthless covaries with the use of fully segmentable forms like painless and sightless, which suggests that they are related in some way. The question is how to state this relation.

Since forms like ruthless cannot be generated by rule, it cannot be argued that the covariation between semi-opaque and fully segmentable forms arises from a single rule that is relied on by different language users to different degrees. In fact, it is unlikely

even that the fully segmentable forms are generated by rule (Baayen \& Hay 2005). The observed correlations make more sense therefore if we look for a relation at the level of lexical storage. If we assume that lexical storage is organized through relations of similarity (Bybee \& Slobin 1982; Bybee \& McClelland 2005) language users who have easier access to, for instance, the group of fully segmentable -less-derivations will have easier access also to semi-opaque forms on -less, which are not only formally but also to some extent semantically similar. The findings are thus most compatible with the idea that lexical items are organized into schemas. The existence of rules, at some level, cannot be excluded from the findings, but if morphological rules exist they must exist next to schematic organization.

Further, if language users link forms like ruthless to other-less-forms, this implies that they treat the -less of ruthless as identical or at least similar to the -less in the seg- 
mentable forms. By this, semi-opaque forms are themselves conveyed some degree of segmentability and compositionality, supporting a gradualist view of segmentability (Baayen \& Hay 2005). This slight degree of segmentability, presumably, is what allows the process of backformation to take place, for example as happened recently when semi-opaque peevish 'causing annoyance' gave rise to the noun peeve 'source of annoyance' (OED s.v. peeve). In this sense, backformation could be regarded as a natural diachronic reflex of the synchronic relations between semi-opaque and fully segmentable forms suggested by the empirical data presented above (cf. Becker 1994; Bauer 2001: 91).

\section{Conclusions}

The case-study on semi-opaque derivations corroborates the idea that words are organized into schemas on the basis of formal and semantic similarity. Specifically, it shows that semi-opaque forms retain relations to the derivational paradigm from which they historically derive. Language users are more likely to use a specific semi-opaque derivation if they rely more heavily on the related derivational pattern. Since this usage correlation cannot be captured by morphological rules, it must reflect some form of organization at the level of lexical storage. It has been proposed that the notion of schema (Bybee \& Slobin 1982; Bybee \& McClelland 2005) can capture the relevant relation.

The other contribution of the case-study, however, is not in corroborating a relatively well-established view on morphological structure (at least as far as derivational morphology is concerned) but in suggesting an alternative method to tap into mental representations. The method proposed here relies on taking a somewhat unusual approach to variation, studying it not from a language-external perspective but from a lan- 
guage-internal perspective. Put differently, the focus here has not been on what a language user's social or geographical profile can predict about their linguistic behaviour, but on what one feature of linguistic behaviour in a user might predict about other features of their linguistic behaviour. Using this information, it is possible to test hypotheses about how language is organized.

As pointed out throughout the preceding analysis, there are still various problems with this general approach. One is finding the right corpus. The NYTAC, which has been used here, is probably not ideal, although the results arrived at to some extent justify its use. At least there can be no denying that the usage patterns that have been unearthed are linguistic facts that need to be explained - and they would seem hard to explain as somehow resulting from the specific type of texts used.

A more direct challenge is refining the statistical techniques employed for uncovering relations in the data. It is unfortunate, for instance, that in the present case-study nothing could be said about the strength of the predictive relations between suffix-usage and usage of specific semi-opaque forms. This is due to the relatively low frequency of the items examined, the resulting skewed distributions for token frequency measures and also to the differences in frequency between items that cause measures for one item to be more accurate than for another. The last issue might be solved (or rather remedied) by clever sampling of the data, but the others simply put limits on the kind of casestudies that can be undertaken, as a larger corpus that is still internally homogeneous is simply out of reach.

A final serious problem is that it is unlikely that variation ever correlates with only a single language-internal factor. In the case-study, this has to some extent been controlled for by means of control adjectives, giving an idea of the impact of topical variation and broad semantic usage preferences on the correlations in the data. It is for- 
tunate that these factors appeared to have relatively little impact in the present casestudy, but if this had not been the case, a more principled way of addressing these issues would have been called for. In any event, serious thought must be given to this if the method is to be developed further. What is needed, after all, is not just a way of integrating different factors in a single model, for which solutions are at hand, but also a better understanding of the factors themselves - for instance, do lexical items differ from one another in topic-sensitivity and how could this be measured?

That said, developing the method further is still an attractive prospect. As hinted above, there are various claims with respect to the cognitive organization of language that could conceivably be tested with respect to the variation across individual language users - for instance, the factors that make constructions productive, the organization of lexical and grammatical categories, or the relations between the inflectional forms of a single verb. The method might also be exploited to corroborate analyses of specific constructions or morphological patterns. Finally, the focus on patterns in individuals' usage is, I believe, a logical consequence of viewing language not only as a social phenomenon that arises in interaction but also as a cognitive phenomenon that has to be mentally represented and, ultimately, carried around in individual heads.

\section{References}

Baayen, R. Harald. 2008. Analyzing linguistic data. A practical introduction to statistics using $R$. Cambridge: Cambridge University Press.

Bauer, Laurie. 2001. Morphological productivity. Cambridge: Cambridge University Press. 
Becker, Thomas. 1994. Back-formation, cross-formation, and 'bracketing paradoxes' in Paradigmatic Morphology. In Geert Booij and Jaap van Marle (eds.). Yearbook of morphology 1993. Dordrecht: Kluwer. 1-26.

Bybee, Joan. 2006. From usage to grammar. The mind's response to repetition. Language 82: 711-733.

Bybee, Joan and James L. McClelland. 2005. Alternatives to the combinatorial paradigm of linguistic theory based on domain general principles of human cognition. The Linguistic Review 22: 381-410.

Bybee, Joan and Dan I. Slobin. 1982. Rules and schemas in the development and use of the English past tense. Language 58: 265-289.

Hay, Jennifer B. and R. Harald Baayen. 2005. Shifting paradigms. Gradient structure in morphology. Trends in Cognitive Sciences 9: 342-348. 